\title{
THE
}

\section{Incomplete Information and Adverse Impacts of Environmental Cleanup}

Corey Lang

University of Rhode Island, clang@uri.edu

Patrick Cavanagh

University of Rhode Island

Follow this and additional works at: https://digitalcommons.uri.edu/enre_facpubs

The University of Rhode Island Faculty have made this article openly available.

Please let us know how Open Access to this research benefits you.

This is a pre-publication author manuscript of the final, published article.

Terms of Use

This article is made available under the terms and conditions applicable towards Open Access Policy Articles, as set forth in our Terms of Use.

\section{Citation/Publisher Attribution}

Lang, C., \& Cavanagh, P. (2018). Incomplete Information and Adverse Impacts of Environmental Cleanup. Land Economics, 94(3), 386-404.

Available at: http://dx.doi.org/10.3368/le.94.3.386

This Article is brought to you for free and open access by the Environmental and Natural Resource Economics at DigitalCommons@URI. It has been accepted for inclusion in Environmental and Natural Resource Economics Faculty Publications by an authorized administrator of DigitalCommons@URI. For more information, please contact digitalcommons-group@uri.edu. 
Forthcoming, Land Economics

\title{
INCOMPLETE INFORMATION AND ADVERSE IMPACTS \\ OF ENVIRONMENTAL CLEANUP
}

\author{
Corey Lang* and Patrick Cavanagh \\ University of Rhode Island
}

\begin{abstract}
This paper uses the hedonic method to examine the external effects of Rhode Island's voluntary brownfield program. We hypothesize that housing price impacts are a combination of valuation of environmental improvement and response to information disclosure initiated by remediation. The results indicate that housing prices decline after nearby remediation, suggesting incomplete information about the presence of risk. Further, we find empirical evidence that price impacts and the degree of incomplete information are different across neighborhoods. Specifically, low housing value neighborhoods experience price declines following remediation while high value neighborhoods experience price increases, leading to an overall regressive impact.
\end{abstract}

Keywords: brownfield, remediation, hedonic valuation, distributional impacts, environmental justice

JEL codes: D63, Q51, I18

\footnotetext{
* Corresponding author. 214 Coastal Institute, 1 Greenhouse Rd., Kingston, RI, 02881. Email: clang@uri.edu. Lang is Associate Professor in Environmental and Natural Resource Economics at University of Rhode Island, where Cavanagh is a graduate student. We thank Andrew Boslett, Dennis Guignet, Josh Linn, Karen Sullivan, Patrick Walsh, Randy Walsh, seminar participants at EPA NCEE, conference participants at New Directions in the Analysis of Environmental Justice at Duke University, and particularly one anonymous referee for valuable comments. This research was supported by the URI Coastal Institute.
} 


\section{INTRODUCTION}

A brownfield is a property that is polluted or contaminated with hazardous waste, which hinders its redevelopment or reuse. Proponents of brownfield remediation point to many benefits of cleanup: health and safety of neighborhood residents, revitalization of urban areas, and mitigation of urban sprawl. The Government Accountability Office (2005) estimates that 450,000 brownfields exist nationwide in the United States, and many cities and states have ongoing agendas to remediate their sites.

Brownfield prevalence is unequally distributed by income, race, and ethnicity, which raises concerns about environmental justice. This type of unequal exposure is common and well documented across criteria air pollutants, toxic air pollutants, and hazardous waste sites (e.g., United Church of Christ 1987, Brooks and Sethi 1997, Shaikh and Loomis 1999, Apelberg et al. 2005, Pastor et al. 2005). ${ }^{1}$ Given unequal exposure, environmental improvement could lead to disproportional benefits for disadvantaged groups, as found by Bento et al. (2015) in the case of the 1990 Clean Air Act Amendments. Thus, a program aimed at cleaning and developing brownfields would intuitively have a disproportionately positive impact on low-income and minority communities. However, this progressive outcome relies on several assumptions, including that information about environmental quality is equal across neighborhoods.

The purpose of this paper is to estimate the external impacts of brownfield remediation in the residential property market and to examine heterogeneous impacts across neighborhoods and the distributional consequences of that heterogeneity. We examine a voluntary brownfield remediation program in Rhode Island ${ }^{2}$, in which the state offered to negate liability in exchange for owners assessing and, if necessary, remediating property to comply with toxicity regulations. Unlike a superfund site, properties may not be known to be brownfields until there is an environmental assessment as part of a sale or redevelopment. There is no database of existing brownfields in Rhode Island, only records of those that have been remediated. Thus, the process of remediation can reveal information previously unknown about a specific property, as well as raise concerns about risks of nearby properties. The presence of this incomplete information,

\footnotetext{
${ }^{1}$ An additional set of papers seeks to disentangle whether it is inequality at the siting stage or if household mobility and housing market dynamics lead to the unequal exposure observed in the cross section (e.g., Been 1994, Depro et al. 2015).

${ }^{2}$ The State of Rhode Island is one of the oldest industrial centers in the United States, staking claim to Birthplace of the American Industrial Revolution with the opening of the first American water-powered cotton spinning mill in 1789. Not surprisingly, most industrial activity is gone, but its remnants remain.
} 
how it differs across neighborhoods, and how it impacts the house price response of remediation and distribution of benefits are the central research questions of this paper.

We observe 225 brownfields identified and cleaned over the period 2003-2013 and 43,787 housing transactions within two kilometers $(\mathrm{km})$ of those remediated sites. Our empirical method to assess the property value impacts of remediation is a dose-response model, in which we regress prices on a continuous measure of brownfield density. Our model also includes census block group and year fixed effects, as well as time-varying neighborhood variables such foreclosure rates. Prior work on brownfield remediation (e.g., Haninger et al. 2017) has used difference-in-differences methods, essentially comparing properties near a site to those further away before and after remediation. In our sample, however, brownfields are often tightly clustered $-79 \%$ are within $1 \mathrm{~km}$ of another site - which makes identifying a control group difficult. $^{3}$

Results from our basic model suggest that remediation reduces nearby property values. The marginal effect of a single remediation $1 \mathrm{~km}$ from a house is $-1.0 \%$. If a house was just 0.5 $\mathrm{km}$ from the brownfield site, the price impact would be -2.0\%. Estimated impacts can be a combination of valuation of environmental improvement, consequences of information learned from cleanup, site characteristics, reuse choices, preference-based sorting following cleanup, and bias resulting from unobserved variables. Given our modeling strategy and additional empirical findings including immediate capitalization and consistency of impacts across site and reuse types, we argue that the price impact is composed only of a valuation effect and an information effect. As an illustration of this intuition, Figure 1 presents a hedonic price schedule for environmental quality. ${ }^{4}$ Suppose residents and potential buyers believe the environmental quality to be $z_{3}$, however these beliefs are incorrect and the actual environmental quality is $z_{1}$. Brownfield remediation improves environmental quality to $z_{2}$, but also reveals the true baseline environmental quality. On net, remediation reduces housing prices from $P\left(z_{3}\right)$ to $P\left(z_{2}\right)$. In this light, we interpret our basic results as evidence that remediation led to significant information revelation, and the negative impact outweighed any valuation effect on sales prices of nearby

\footnotetext{
${ }^{3}$ Despite the limitations, we also estimate difference-in-differences models to make sure our modeling assumptions are not driving the results. We present these results in the online appendix and conclusions are similar.

${ }^{4}$ For a complete discussion of the underlying theory that leads to the hedonic price schedule, refer to Taylor (2017).
} 
properties. This conclusion is supported by other empirical findings of information disclosure affecting the implicit price of different amenities (e.g., Pope 2008, Guignet 2013).

To explore distributional impacts and environmental justice concerns, we examine how house price responses may be different in neighborhoods with different socioeconomic characteristics. We build on recent work showing how the housing market is segmented (Kuminoff and Pope 2013, Landvoigt et al. 2015) and examine how the impacts of remediation may differ by market segment. Specifically, we investigate price responses in low, medium and high priced neighborhoods, and we posit that valuation and information may be different across these segments. These results suggest that remediation leads to price declines in low home value neighborhoods, whereas in high home value neighborhoods remediation leads to price increases. Further, in low value areas, proximity to unremediated brownfields does not impact prices, but in high value areas sales prices are less when near an unremediated brownfield. Together, these results give support and nuance to our conclusion that incomplete information is affecting price impacts. Low value areas appear to be less informed about existing brownfields and remediation reveals information, which leads to price declines (same as the example above illustrated using Figure 1). However, high value areas appear to be more informed about existing brownfields and valuation of remediation dominates the price effect of information. On Figure 1, this would be a move from $z_{3}$ to $z_{4}$. Further, these results indicate adverse distributional consequences of remediation as low-income and minority households disproportionately live in low house value neighborhoods.

This article makes several contributions to the literature. First, this article serves as an evaluation of a brownfield remediation program, of which evidence is scant. ${ }^{5}$ Voluntary brownfield remediation programs are common across many states and large cities, and thus empirical evidence on their effects is needed. Using data from Chicago, Linn (2013), which is the most closely related study to ours in terms of design, estimates that the marginal effect of a single remediation in the prior year $1 \mathrm{~km}$ away is a $0.2 \%$ price increase. Haninger et al. (2017) find large, positive property value impacts of brownfield remediation, ranging from $5 \%$ to $15 \%$, using a national sample of sites that received an EPA grant for cleanup. Why may our results differ in sign and what can be learned from differences? In contrast to this paper, Haninger et al.

\footnotetext{
${ }^{5}$ However, many evaluations of superfund remediation exist (e.g., Messer et al. 2006, Kiel and Williams 2007, Greenstone and Gallagher 2008, Gamper-Rabindran and Timmins 2013, Mastromonaco 2014).
} 
examine sites that are toxic enough to warrant federal cleanup funding. ${ }^{6}$ Thus, in their case, it may be less likely for remedial activity to be a source of new information for nearby residents. Further, the EPA awards grants based in part on community involvement and allows communities to have input into reuse; officials in EPA's Office of Solid Waste and Emergency Response feel this may be a critical difference between programs based on their experience (Cooper et al. 2015). Additionally, federal cleanup money is often coupled with activities like community outreach and promotion of development, and job training grants can be awarded to cleanup communities too (EPA 2014), all of which could factor into estimated benefits. In contrast, under voluntary programs, the decision to remediate is often driven by development rather than toxicity, and the discovery of contamination may be new information. The context of Linn (2013) is another voluntary brownfields program that targets less toxic sites and exchanges liability for remediation. The magnitude of Linn's estimates are much smaller than Haninger et al., which corroborates the idea that funding, community engagement or the degree of toxicity are important determinants of price effects.

Second, this paper contributes to our understanding of how environmental policy can be regressive, a concern notably raised by Baumol and Oates (1988). When a policy is place-based, the main concern is that property values rise, but low-income renters do not receive the capitalization benefits and may be priced out of a neighborhood and suffer a welfare loss with relocation (Fullerton 2011). ${ }^{7}$ In contrast to these indirect means of regressive outcomes, this paper finds that environmental improvement reduces property values in low-income neighborhoods and increases values in high income areas. For the lowest income quintile, the ratio of annualized change in home value resulting from remediation to income is $-2.5 \%$; for highest income quintile, this same ratio is $+0.5 \%$. In contrast, Gamper-Rabindran and Timmins (2013) examine distributional impacts of superfund remediation and find that low value homes appreciate more than high value homes after cleanup. One possible explanation for this divergence in results is incomplete information about existing contamination in the case of brownfields, which is unlikely for a superfund site.

\footnotetext{
${ }^{6}$ Using the website "Cleanups in my Community” (http://www2.epa.gov/cleanups/cleanups-my-community), we found little overlap (<5\%) between our sample sites and those that received EPA grants.

${ }^{7}$ The empirical evidence supporting this idea, however, is mixed (Sieg et al. 2004, Grainger 2012, Bento et al. 2015, Lang 2015).
} 
Lastly, hedonic valuation is a workhorse model in environmental economics, and typically estimated coefficients are interpreted as marginal willingness to pay (MWTP). However, there are myriad factors that can cause hedonic coefficients to separate from valuation (Kuminoff and Pope 2014), and this paper adds empirical evidence that casts doubt on this interpretation. Currie et al. (2014) find that property value impacts do not reflect the full extent of health impacts caused by manufacturing plants. Guignet (2013) finds that property prices only respond to water quality variation when home-specific well tests are done. Pope (2008) and Walsh and Mui (2017) show that the hedonic price gradient changes after mandatory information disclosure. Given health and safety concerns of brownfields, certainly the welfare of nearby residents improves with remediation, all else equal. However, our findings indicate that price changes do not reflect health and safety improvements and this wedge is likely driven by incomplete information.

\section{BACKGROUND}

\subsection{Brownfields}

A brownfield is a property that is polluted or contaminated with hazardous waste, which hinders its redevelopment or reuse. ${ }^{8}$ In Rhode Island, the most common sources of contamination for brownfield sites are heavy metals (predominantly Arsenic and Lead), petroleum related byproducts (from leaking storage tanks and spills), Polychlorinated Biphenyls (from electrical transformers and substations), and historical remnants of the state's manufacturing background.

Inorganic heavy metals remain and the soils become sinks for these contaminants to leach into proximate ecosystems and food chains (Wuana and Okieimen 2011). In Rhode Island, industrialization started in the late 18th century with the onset of textile mills harnessing the power of local waterways. These mills later supported the manufacturing of tools, alloys and jewelry - industries that resulted in lasting heavy metal contamination. The high concentration of historical manufacturing centers along with the toxicity and mobility of contaminants over a two century period point to the large degree of uncertainty that investigators, regulators, and land owners encounter when attempting to sufficiently mitigate risk to humans and the natural environment.

\footnotetext{
${ }^{8}$ See www.epa.gov/brownfields for more information.
} 
Hazardous wastes harbored within brownfields can have a predictable effect on the people that come into contact with them and their surroundings: unusual rates and rare forms of cancer (Cogliano 1998), birth defects and abnormal human development (Croen et al. 1997), and learning disabilities (Ciesielski et al. 2012).

\subsection{Remediation}

Banks, lenders, and corporate property buyers typically require real estate to have a site investigation on record before going forward with any transactions or development that may carry the risk of a hazardous waste liability. A site investigation is the initial assessment and testing of a property that determines if there are contaminants present and whether those contaminants exceed critical thresholds. These requirements change from state to state but are commonly based on the EPA's recommendations. If a contaminant is found to exceed the state threshold, the site is deemed hazardous and in need of cleanup (remediation) under state or federal law. Cleanup typically takes less than six months.

Remediation efforts aim to clean up the source of pollution and otherwise isolate the pathways in which the contaminants could affect humans, with the ideal goal being to restore the environmental health of the site to its pre-polluted state. Additionally, remediation can allow for the reuse of the land that would otherwise sit abandoned and hazardous.

The historic nature of many brownfields can lead to a contaminated parcel of land changing hands one or more times, which creates a legal buffer between the current land owner and the historic polluter. The contemporary land owner is held legally liable for the cleanup costs associated with any hazardous waste discovered on their property, regardless of whether they were aware of the waste at the time of their purchasing the property.

\subsection{Rhode Island's voluntary brownfield program}

State governments focus on brownfields that are not so imminently hazardous as to warrant federal attention, but still present an environmental risk. Further, states and others see brownfield remediation and redevelopment as an important strategy in revitalizing urban neighborhoods and reducing urban sprawl. State level equivalents of the EPA manage cleanup efforts within their jurisdiction and will sometimes establish a voluntary brownfields program. 
Voluntary programs have been accredited for a notable increase in the number of brownfield cleanups since their introduction (Linn 2013).

In Rhode Island, the Site Remediation and Brownfields Program was created in 1993 by the Rhode Island Department of Environmental Management (RIDEM) Office of Waste Management (OWM). ${ }^{9}$ This program offers some legal protection for land owners that report a release of contaminants to RIDEM and agree to follow and complete the official remediation process outlined in the Rules and Regulations for the Investigation and Remediation of Hazardous Material Releases. Properties can be brought into the program either by voluntary entry for purpose of owners avoiding liability or by performing an environmental site assessment to clear the way for a real estate transaction. While it is voluntary for property owners to enter the program, this is misleading. After a site investigation has been conducted, the results are required to be reported to RIDEM. Thus, the choice not to enter the program would likely have legal ramifications. Once in the program, RIDEM works with the property owner to determine the best path forward that both minimizes the risk of human exposure and keeps cleanup costs at acceptable levels.

Given the possible ignorance of current owners over the toxicity of their property, nearby residents may be uninformed as well, and Rhode Island's program seeks to address this. Contaminated site owners are required by RIDEM to publicly notify the owners of land parcels that abut a brownfield parcel on two separate occasions throughout the remediation process. ${ }^{10}$ The first time, abutters are notified of a pending site investigation to further investigate a suspected contamination. When the investigation is completed, the results of any findings are presented to abutters in the second notification, along with several remedial alternatives that are likely to take place. There is no public notification when remediation is complete. ${ }^{11}$ However, abutters have no legal obligation to inform prospective buyers (as in Pope 2008). While formal notification stops at current abutters, information is likely to spread further through observation of cleanup and through banks, which monitor areas of potential liabilities.

\footnotetext{
${ }^{9}$ For more information, see www.dem.ri.gov/brownfields/default.htm

${ }^{10}$ See rule 7.07 of the Rules and Regulations for the Investigation and Remediation of Hazardous Material Releases http://www.dem.ri.gov/pubs/regs/regs/waste/remreg11.pdf

11 There are stipulations for special circumstances, such as the repurposing of a brownfield for use as a school, that warrant more extensive public outreach.
} 


\section{DATA}

\subsection{Brownfield data}

Brownfield remediation data were gathered from the public record, provided by the RIDEM OWM. We collected data on all sites remediated from October 2003 to March 2013. Prior to October 2003, the EPA did not require states to make data on remedial actions publically available, and RIDEM chose not to keep records. ${ }^{12}$ The RIDEM data included the name of each site, the approximate street address, site acreage, general source of contamination, and the date that the letter of completion was issued. The dataset did not include entry dates into the state brownfield remediation program. Combining address records from RIDEM with Google Maps, Google Earth, plat and parcel maps and tax assessor databases, we were able to identify exact longitude and latitude at the center of each brownfield parcel.

During our time range, a total of 225 sites were remediated and this forms our sample. Figure A1 in the online appendix shows the geographic distribution of the sample brownfields. The highest concentration of brownfield sites is in the urban corridor of Providence. Other areas of high concentration tend to be located near major rivers, such as the Blackstone flowing south from Massachusetts into Providence, and along Narragansett Bay, both reflecting historical patterns of industry.

RIDEM identified sites by their prior function or the primary source of contamination. Using this, we group all sample sites into three broad classifications: 'Historical' meaning a site used industrially many decades prior, 'Synthetic compounds’ including heavy metals and Polychlorinated Biphenyls, and ‘Petroleum’ indicating oil contamination usually from underground storage tanks. Historical is the largest comprising 48\%; Synthetic compounds and Petroleum make up $18 \%$ and 15\%, respectively. The remaining $19 \%$ are either classified as something uncommon or unclassified.

To complement the source contamination data, we manually collected reuse data. Using Google Maps, we determined how each sample remediated site is currently being used. 42\% are used commercially and 18\% are used for industrial purposes. 25\% are redeveloped into residential areas or schools; the remediation burden is greater for this reuse because standards are

\footnotetext{
${ }^{12}$ Not having remediation data prior to 2003 is a limitation of our study. We guard against prior remediation biasing our results by including census block group fixed effects, which control time-invariant neighborhood attributes, such as pre-2003 remediation.
} 
more stringent. 15\% were either classified as something uncommon or had not yet been developed. Table A1 in the online appendix summarizes the distribution of our sample into source contamination and reuse categories, as well as the transition frequency between groups.

\subsection{Housing data}

Our housing data were purchased from Warren Group and include nearly all Rhode Island transactions between October 2003 and February 2013. We have transactions data back to January 2000, which are used to measure pre-sample neighborhood average prices as described in Section 4. The data offer information on sales price, date of transaction, street address, living square feet, lot size, year of construction, number of bedrooms, full and half bathrooms, and whether or not the unit has a pool, fireplace, air conditioning or view of the water. Sales prices were adjusted for inflation using Federal Housing Finance Agency's monthly Housing Price Index and brought to February 2013 levels. To get latitude and longitude, we geocoded all addresses to coordinates using the Rhode Island GIS E-911 geolocater. ${ }^{13}$ Using GIS, we calculated the Euclidian distance to all brownfields.

To build our main sample, we include only transactions within $2 \mathrm{~km}$ of a site in order to exclude neighborhoods and properties dissimilar to those that experience remediation. We include only arm's length transactions of single family homes. Lastly, we dropped sales with prices less than $\$ 25,000$ and greater than $\$ 10$ million. The final sample is 43,787 transactions representing 34,035 unique single family properties.

We additionally added a set of spatial amenity variables using GIS. While foreclosure properties are not included in the main sample, we calculate the number of foreclosed properties per block group-year in order to control for price spillovers from those properties - consistent with Harding et al. (2009). Additionally, we calculate proximity to several time-invarient neighborhood features: highway exit, village center, major river, large lake, coastline, industrial center, Enterprise Zone, and to downtown Providence. One additional distance was taken to the nearest pre-sample CERCLIS site. Only sites on CERCLIS before the sample period began were included in order to gain a sense of how close each transaction was to a pre-sample hazardous waste site that warranted federal level attention.

\footnotetext{
${ }^{13}$ Available at http://www.edc.uri.edu/rigis/.
} 


\subsection{Brownfield density index}

Many hedonic analyses apply difference-in-differences, where proximity to a changing amenity or disamenity define treatment and properties beyond a certain distance threshold are control units. However, in instances in which the attribute of interest is densely distributed and households can be impacted by multiple treatments, a simple distance variable is unlikely to sufficiently capture exposure. In our sample of 225 brownfields, 55\% are within $0.5 \mathrm{~km}$ of another brownfield, 79\% are within $1.0 \mathrm{~km}$ of another brownfield, and 92\% are within $2.0 \mathrm{~km}$ of another brownfield. Because the spatial extent of effect is unknown, identifying a clear control group for most of our sample is difficult, and a difference-in-differences methodology is less appropriate than a continuous measure of exposure.

To measure exposure in our setting, we develop a brownfield density index (BDI) that can incorporate multiple, proximate brownfields. $B D I$ assigns each transaction a continuous value that weights the proximity to remediated brownfields based upon the inverse distance to a transaction. Closer brownfields carry more weight, while those further away contribute less. This construction follows Linn (2013), who examined the similarly dense brownfield area of Chicago.

We calculate several measures of BDI. The first, which is the key independent variable for most of our analyses, is the sum of the inverse distances to all brownfields within $2 \mathrm{~km}$ that are remediated prior to the transaction.

$$
B D I_{i}=\sum_{J} \frac{1}{d_{i, \mathrm{j}}} \cdot 1\left(t_{i}>t_{j}\right) \cdot 1\left(d_{i, \mathrm{j}}<2 k m\right)
$$

where $J$ indexes all brownfields in our sample, $d_{i, j}$ is the distance between house transaction $i$ and brownfield $j$, and we limit the range of influence to be $2 \mathrm{~km} . t_{i}$ is the date of transaction for housing transaction $i$, and $t_{j}$ is the date of completed remediation for brownfield $j$. Numerical examples help translate $B D I$ into real experience. $B D I$ would equal one if a single brownfield located $1 \mathrm{~km}$ from a house was remediated prior to the house's transaction. Alternatively, if a house was $2 \mathrm{~km}$ from two brownfields that were remediated before the transaction, then $B D I$ would also be one. Since the relationship with distance is inverse, a house located just .1 km from a remediated brownfield would have a $B D I$ of 10 . Due to the inverse nature, observations far from brownfields have a disproportionately small influence on estimating the relationship between remediation and housing prices, and as a result altering the $2 \mathrm{~km}$ cutoff does not qualitatively change results. 
Second, we develop three $B D I$ measures that distinguish time since remediation in order to allow heterogeneity in the effect on house prices over time. For example, remediation may be an immediate negative impact on nearby property values due to information revelation, but this effect may become zero or even positive as more time passes as households adjust to the situation and value the improvement. The first of the three measures is the density of remediated brownfields occurring less than six months before housing transaction $i$ :

$$
B D I_{-} 0_{-} 6_{i}=\sum_{J} \frac{1}{d_{i, \mathrm{j}}} \cdot 1\left(t_{i} \in\left(t_{j}, t_{j}+6\right)\right) \cdot 1\left(d_{i, \mathrm{j}}<2 k m\right)
$$

where and $t_{j}+6$ is six months after brownfield $j$ is remediated. The second and third BDI measures in this group use time windows of 6-18 months and more than 18 months.

Lastly, we create a time-invariant measure of brownfield density that captures the sum of inverse distances to all brownfields, regardless of remediation status.

$$
{\text { BDI } \text { total }_{i}}=\sum_{J} \frac{1}{d_{i, \mathrm{j}}} \cdot 1\left(d_{i, \mathrm{j}}<2 \mathrm{~km}\right)
$$

We use this variable (in a specification that includes $B D I_{i}$ ) to test the effect of unremediated brownfields on property prices. More details on model specifications are given in Section 4.

\subsection{Summary statistics}

Table 1 presents summary statistics that explain the data and illustrate the setting. In addition to brownfield and housing characteristics, we include Census 2000 block group data to understand resident characteristics. ${ }^{14}$ Column 1 presents basic means. The average BDI of a transacting property is 1.979 , while average $B D I$ total is 4.528 indicating that the average transaction is around both remediated and unremediated brownfields. The average sales price is $\$ 248,583$, with just over a quarter-acre lot and just under 1,500 square feet of living area. The average median family income across neighborhoods in our sample is $\$ 47,210$. On average, $26.4 \%$ of our sample has a college degree and $11.2 \%$ are black or Hispanic.

Column 2 compares our sample observations and neighborhoods to out-of-sample areas, namely transactions during the same time frame that are more than $2 \mathrm{~km}$ from any brownfield. The results show that out-of-sample houses sell for over $\$ 75,000$ more, have two-thirds of an

\footnotetext{
${ }^{14}$ Summary statistics for all variables used in regressions are available in Table A2 of the online appendix.
} 
acre larger lot size, more living area, and are more likely to have central AC than in-sample houses. Further, out-of-sample residents have a larger family income by $\$ 9,178$, are 4.6 percentage points more likely to have a college degree, and are 5.4 percentage points less likely to be non-white.

Columns 3 and 4 assess correlations between the housing and neighborhood characteristics and $B D I$. Each variable was separately regressed on $B D I$, and in Column 4 block group fixed effects were additionally included. Column 3 shows that BDI has strong, unconditional correlations with nearly all the housing and neighborhood characteristics. The correlations suggest that houses with high $B D I$ have lower sales prices, smaller lots, less central AC and fewer bathrooms. Additionally, residents in high BDI areas have lower income, are less likely to have gone to college, and are more likely to be non-white. All of these correlations are consistent with intuition about environmental disamenities and environmental injustice. A concern is that if there are observable differences between high and low $B D I$ areas, there may also be unobservable differences that bias regression estimates. However, when controlling for block group fixed effects, most correlations other than price become statistically insignificant or much smaller in magnitude. Our preferred regression specifications include block group fixed effects (or property fixed effects), which mitigates fears of unobservable variables biasing estimates.

\section{Methodology}

We use the hedonic price method to estimate the effects of brownfield remediation on proximate housing prices. Our basic specification is:

$$
\ln \left(p_{i}\right)=\beta B D I_{i}+X_{i} \varphi+\varepsilon_{i}
$$

where $p_{i}$ is the sales price of transaction $i, B D I_{i}$ is as defined in Equation (1), $X_{i}$ is a set of housing, location, and temporal controls and will be discussed in detail below, and $\varepsilon_{i}$ is the error term. $\beta$ is the coefficient of interest and measures the effect of density of remediated brownfields on housing prices. As discussed in the introduction, we interpret $\beta$ as the combination of household valuation of environmental improvement and any consequence resulting from new information derived by remediation by households, lenders, or developers. Assuming valuation of environmental improvement is positive and new disclosure of old contamination is negative, a positive $\beta$ would suggest household valuation of environmental improvement overwhelms any 
negative effect of new information. Whereas a negative $\beta$ may be interpreted as the negative impact of information revelation being larger than the valuation.

First, $X_{i}$ includes structural housing characteristics (e.g., bedrooms, bathrooms) and measures of spatially-referenced attributes (e.g., distance to the coast, distance to pre-2003 CERCLIS sites). Second, to guard against spatially correlated unobserved variables, we include fixed effects for each Census block group, of which there are 616 in our sample with an average of 71.1 observations per block group. Third, the time span of our study includes the boom and bust of the housing market (see Figure A2 in the online appendix for the overall time trend observed), and we include month-year fixed effects to negate any correlation between macroeconomic conditions and remediation activity.

However, recent research has shown that the boom-bust cycle was not uniform across space, even for neighborhoods within the same state or metropolitan area (Kuminoff and Pope 2013). Further, Landvoigt et al. (2015) find that lower tier neighborhoods appreciated much more than upper tier neighborhoods in the boom part of the cycle, and that this was driven by the expansion of lending to subprime credit households. In our data, we find similar price dynamics (see Figures A3a and A3b in the online appendix). Given that properties and neighborhoods with high $B D I$ tend to have lower sales prices and lower incomes, these differential price movements pose a challenge to identification.

To account for these predictable, differential price trends across segments of the housing market, we include three additional sets of variables in $X_{i}$. First, we include town-year fixed effects to non-parametrically control for differing boom-bust cycles across the 35 towns in our sample. Second, we calculate the number of foreclosures occurring by year and block group and include this as an independent variable. Third, we calculate average pre-sample (January 2000December 2002) house prices for each census tract and interact this continuous variable with year-quarter fixed effects. This set of variables controls for different price segments of the market evolving differently. ${ }^{15}$ In a robustness check, we alternatively control for propertyspecific pre-sample price interacted with year-quarter fixed effects, similar to Bajari et al. (2012).

\footnotetext{
${ }^{15}$ Linn (2013) also includes pre-sample mean neighborhood prices interacted with time fixed effects, however, his motivation is to control for reverse causality. He argues that because property values incorporate expected future changes in value, including these variables will control for unobserved neighborhood trends.
} 
In addition to Equation (4), we estimate models allow the effect of remediation to change in the time since remediation:

$$
\ln \left(p_{i}\right)=\beta_{1} B D I \_0 \_6_{i}+\beta_{2} B D I \_6 \_18_{i}+\beta_{3} B D I \_18 p l u s_{i}+X_{i} \varphi+\varepsilon_{i}
$$

where $B D I \_0 \_6_{i}$ is as defined in Equation (2) and BDI_6_18 $i$ and BDI_18plus $i$ are defined analogously.

In Equations (4) and (5), identification comes from within block group variation. While these are small geographic areas, there could still be a concern that there are unobserved variables that vary within block groups and are correlated with both house prices and $B D I$. We employ two additional models to guard against this bias. First, we estimate a repeat sales model and include property specific fixed effects:

$$
\ln \left(p_{i t}\right)=\beta B D I_{i t}+X_{i t} \varphi+\alpha_{i}+\varepsilon_{i t}
$$

where $t$ denotes the time of sale. This model will capture all time-invariant spatial variables, but at the expense of losing $60 \%$ of our observations. Second, in an effort to capture unobserved variables correlated with $B D I$, we add BDI total, defined in Equation (3), to Equation (5):

$$
\ln \left(p_{i}\right)=\beta B D I_{i}+\gamma B D I \text { total }_{i}+X_{i} \varphi+\varepsilon_{i}
$$

Not only does the inclusion of BDI total improve the identification of $\beta$, but the interpretation of $\gamma$ can provide insights into the disamenity value of proximity to unremediated brownfields. ${ }^{16}$ If $\gamma$ is negative, this would suggest the community and potential buyers are aware of the brownfield and its associated risks and value non-proximate houses more. However, if this coefficient is zero, then the community and potential buyers may not value distance or may not be aware of the proximate hazards.

Lastly, we estimate variants of Equations (4), (6) and (7) that allow for heterogeneous impacts of remediation across space. We divide the sample into terciles of low, medium and high priced neighborhoods based on the average pre-sample (2000-2002) sales prices for each census tract. We then estimate models that interact indicator variables for each tercile with $B D I$ and $B D I$ total. These models enable inference into the price impact of remediated and unremediated sites by neighborhood wealth, which could be correlated with valuation of environmental goods,

\footnotetext{
${ }^{16}$ Instead of the time invariant BDI total, it is tempting to include a measure of BDI for only unremediated brownfields. The problem with that switch is that $B D I$ and $B D I$ unremediated are highly collinear because remediation of a brownfield would decrease BDI unremediated and increase BDI by the same amount. As a result, including BDI unremediated dramatically changes the coefficient on BDI and its interpretation.
} 
information about environmental goods, and bank lending practices. We then use the differential price changes to assess distributional impacts.

\section{Results}

\subsection{Basic Results}

Table 2 presents a suite of results from various specifications of Equation (4) in Panel A and Equation (5) in Panel B. Five columns represent five model specifications. Column 1 includes housing and neighborhood characteristics only. Columns 2-5 build on the prior column's specification, adding in turn year-month fixed effects, census block group fixed effects, year-town fixed effects, and pre-sample average house values interacted with year-quarter fixed effects.

Beginning with Panel A, all coefficients show a negative and statistically significant effect of brownfield remediation on property values. The coefficient estimates range from -0.0244 to -0.0100 , are all statistically significant at the $1 \%$ level, and decrease in magnitude as more controls are included. Among specifications in this table, Column 5 is our preferred model because it controls for spatial unobservables, differential housing market fluctuations by town and by market segment. However, the full suite of results suggests that the modeling choice does not qualitatively affect the estimated relationship between $B D I$ and prices, and there is still enough within block group variation to identify the treatment effect. The estimated coefficients from our preferred model suggests that a one unit increase in $B D I$ yields a $1.0 \%$ reduction in house price. This translates into a marginal effect of $-1.0 \%$ for a single remediation $1 \mathrm{~km}$ away, which would be a \$2486 loss in an average house value. The mean value of $B D I$ in our sample is 1.979 , indicating that the average house sold for nearly $2 \%$ less than a house removed from any brownfield remediation, all else equal.

Panel B supports the findings of Panel A, showing statistically significant negative coefficients across the board. The results further suggest the price impacts of remediation are immediate and relatively constant as time goes on. The coefficient on BDI 0-6 months in Column 5 is -0.0080 , stays nearly identical 6-18 months following remediation, and then grows slightly to -0.0116 beyond 18 months. Given the immediate nature of price impacts, it seems very unlikely that preference-based sorting is causing this result because it would take longer for 
populations to turn over. For the remainder of the paper, given the similarity in results, we focus only on models using $B D I$ as the main independent variable, as in Panel A.

These results contrast with Linn (2013), the most closely related study to ours, and Haninger et al. (2017), which both find positive property value impacts of brownfield remediation. Linn (2013) estimates a coefficient of 0.0016 on the density of sites remediated prior to sale. Haninger et al. (2017) find much larger effects, ranging from 5\% to 11\% postremediation, when looking at EPA-funded remediated sites. As discussed in the introduction, a key difference between the EPA sites and Rhode Island's voluntary program sites is that the EPA prioritizes community involvement and information availability prior to remediation. In sum, our results and the differences in programs lend support for the notion that brownfield remediation leads to new information about the environmental quality to buyers, developers or lenders, and prices respond negatively to that new information. As we explore extensions to this model, we will seek more evidence for this interpretation.

\subsection{Robustness checks}

Table 3 presents a series of specification that test the robustness of the results presented in Table 2. Column 1 presents results from estimating Equation (6), the repeat sales model, on the 7,752 properties that transact more than once during our sample time period. The magnitude of effect grows slightly to -0.0134. Column 2 presents results from estimating Equation (7), which includes BDI total. The coefficient on BDI is nearly unchanged from Table 2 Column 5. Both of these results suggest that results are not affected by unobserved variables that vary within block group and are correlated with both house prices and $B D I$. The coefficient on $B D I$ total is small and insignificant, which could indicate that on average there is no disamenity value of unremediated brownfields. However, given the coefficients on BDI, it seems more plausible to interpret this statistical zero as evidence that there is no knowledge of unremediated brownfields.

Columns 3 and 4 show results from models that have alternative strategies for controlling market price segments experiencing the boom-bust cycle differently. Column 3 includes Census tract by year fixed effects, which provide a more flexible way of controlling for neighborhood dynamics than town by year fixed effects and pre-sample neighborhood mean prices interacted 
with year-quarter fixed effects. ${ }^{17}$ The estimated coefficient on BDI is -0.0085 , slightly smaller than when not using tract-year fixed effect, but still consistent with the basic results. Instead of modeling how neighborhood prices evolve through the boom-bust cycle, Column 4 uses presample prices of individual properties as predictors of price fluctuations, similar to the strategy of Bajari et al (2012). Specifically, for sample properties that additionally transact during the time frame January 2000-Septemeber 2003 (22.5\% of the main sample), the pre-sample sales price is interacted with year-quarter fixed effects. The estimated coefficient on BDI is $-0.0187 .^{18}$ Both columns suggest the modeling choice for how price segments experience the price cycle are not consequential for the results.

Columns 5 and 6 modify the definition of $B D I$ by squaring and square rooting inverse distance to give more or less weight, respectively, to closer brownfields. The interpretation of the coefficient changes due to the changing units, but both coefficients are negative and statistically significant, which is consistent with other results. While not shown here, the results are also robust to modifying the $B D I$ definition to only include brownfields within $1.5 \mathrm{~km}$.

As an additional robustness check, we estimate difference-in-differences models for a variety of treatment and control distance bins. The results are presented in in Tables A3 and A4 of the online appendix and strongly support the overall findings of negative price changes.

\subsection{Heterogeneity by neighborhood average house value}

Prices in different types of neighborhoods may respond differently to brownfield remediation. One source of heterogeneity could be wealth levels of a neighborhood and all that is correlated with wealth. Conventional wisdom may suggest that wealthier areas are more informed about environmental amenities, and remediation may not be new (negative) information. If the site is known to be contaminated, remediation may positively affect housing prices. Further, wealthier areas may be viewed as a safer investment for development or redevelopment, and thus developers may be less concerned about discovery and remediation of a brownfield, and prices may not be negatively affected.

\footnotetext{
${ }^{17}$ However, only tracts with sufficient observations could be included to identify tract-year fixed effects, otherwise Stata could not invert the matrices. Thus, only tracts with 200 observations or more were included in this column's sample, which results in a loss of $18.4 \%$ of the main sample. The results are robust to changing the cutoff of 200.

18 The Bajari et al. (2012) strategy is slightly different; they use the estimated residual from a prior sale to control for property unobservables. With the same sample used in Column 4 of Table 3, we estimated such a model and the coefficient on BDI was a statistically significant -0.0278 .
} 
Table 4 presents results from models that allow the house price impact of remediation to vary by neighborhood price level. We estimate three models: the first similar to the preferred specification from Table 2, the second adds BDI total, and a repeat sales model. In each specification, $B D I$ is interacted with indicator variables for low, medium and high price neighborhood, definitions which are based on pre-sample sales and are time-invariant. Additionally, in Column 2, BDI total is interacted with the three indicator variables.

The coefficient on BDI in low price neighborhoods ranges from -0.0181 to -0.0208 and is statistically significant at the $1 \%$ level across all three specifications. For medium price neighborhoods, coefficients on $B D I$ are always negative, but half the magnitude or less of the effect of BDI in low price areas. In contrast, coefficients on $B D I$ in high price neighborhoods are twice positive and statistically significant, suggesting prices increase after remediation or at least do not decrease. In sum, these results reveal substantial and statistically significant heterogeneity in house price responses to remediation between neighborhoods of different house values. ${ }^{19}$

In Column 2, the coefficient estimates on interactions with BDI total also reveal substantial and statistically significant heterogeneity across neighborhood types. The coefficient for BDI total in low price neighborhoods is statistically insignificant and small in magnitude, suggesting that houses located near unremediated brownfields in low price neighborhoods do not sell for a different price than houses further away. In contrast, the coefficients for BDI total in medium and high price neighborhoods are negative and statistically significant, with the coefficient for high price neighborhoods larger in magnitude. This suggests that prices are lower closer to unremediated brownfields in medium and high price neighborhoods.

If we return to the idea that coefficients on $B D I$ reveal the net impact of valuation and new information, the coefficients in Table 4 tell an interesting story consistent with the idea that information is a critical element of price effects. In low price neighborhoods, results suggest that unremediated brownfields are not known to be a risk. Once remediation occurs, prices of proximate houses decline, suggesting new information about contamination is negatively impacting the price new buyers are willing to pay or the amount banks are willing to lend. However, in high price neighborhoods, results suggest that households possess information about

\footnotetext{
${ }^{19}$ An alternative specification that includes $B D I$ as a main effect and $B D I$ interacted with I(medium price neighborhood) and I(high price neighborhood) was used to test statistical differences in price effects across neighborhood types. While the two models are essentially identical, we felt presenting results as in Table 4 better enabled interpretation of coefficients.
} 
unremediated brownfields and place value on non-proximity. Further, we see prices increase after remediation, indicating the valuation effect is larger than the new information effect, which is consistent with households knowing about the brownfield prior to remediation. Interestingly though, it appears some stigma about the location may remain as coefficents on BDI are equal or smaller in magnitude than the coefficient on BDI total, suggesting prices do not fully recover post remediation. In medium price neighborhoods, the results indicate something in between, that households are at least somewhat aware of existing brownfields, but still prices may still decline after remediation, though much less than in low price neighborhoods.

\subsection{Heterogeneity by contamination type and reuse}

One alternative explanation to the heterogeneous price impacts estimated in Table 4 is that there may be different price impacts by type of contamination or reuse, and contamination and reuse patterns may be correlated with neighborhood characteristics. To test this, we create $B D I$ measures specific to each contamination source and each reuse type and then estimate separate regression including only one source or type at a time. Table 5 reports the results. While there are differences in magnitude across contamination sources and reuse types, all coefficients are negative and all but one are statistically significant. These results suggest that correlations between contamination and reuse patterns and neighborhood characteristics are not driving the heterogeneity observed in Table 4.

\section{DisTRIBUTIONAL IMPACTS}

In this section, we extend our analysis to think about how Rhode Island's voluntary brownfield program impacted households across the distribution of wealth levels. We will consider welfare as measured by changes in house price proportional to income, which is commonly used in the literature (Fullerton 2011). Relating impacts to income is similar to thinking about tax incidence, and whether a tax is progressive or regressive. In the case of the impact of brownfield remediation, if welfare improves more for low-income households than high-income households, then the policy is progressive, and regressive if the opposite holds.

In order to calculate our welfare measure, we first multiply sales prices by transaction specific $B D I$ and by the corresponding coefficient estimate from Column 3 of Table 4, which yields the total impact of remediation on sales price. This number is then put in annual terms 
assuming a 5\% interest rate and 30-year mortgage. Annualized impacts are averaged by Census tract and divided by tract median family income from the 2000 Decennial Census to arrive at our welfare measure. A limitation of this analysis is that it does not account for impacts to renters, which on average are lower income than homeowners.

Figure 2 plots welfare impacts against log median family income at the tract level. Each point in the data is given a diameter proportional to the average $B D I$ of all observations within that tract, thus indicating which neighborhoods experienced more remediation. Immediately clear from the figure is a positive relationship between income and welfare. The average welfare impact for each quintile of income, from lowest to highest is: $-0.0250,-0.0075,0.0010,0.0018$, and 0.0055 . These findings suggest a regressive impact of the program.

Given the negative correlation between brownfield prevalence and neighborhood income observed in Table 1, a program aimed at cleaning and developing brownfields could intuitively have a disproportionately positive impact on low-income areas. In the context of air quality, Bento et al. (2015) document a similar correlation between income and environmental quality, and find that the air quality improvements from the 1990 Clean Air Act Amendments disproportionately benefited low-income households. More similar to the context of brownfields, Gamper-Rabindran and Timmins (2013) find that superfund remediation disproportionately benefited low value homes. In the present case of Rhode Island's voluntary brownfield program, however, the empirical evidence suggests a progressive outcome was thwarted by the presence and heterogeneity of incomplete information.

\section{CONCLUSION}

This paper examines the external effects of a voluntary brownfield remediation program in the state of Rhode Island that reduces liability for owners of brownfield sites in exchange for remediation. There are many perceived benefits to brownfield remediation (e.g., reducing adverse impacts on human health, reducing urban sprawl, and promoting economic growth in inner cities), which makes it a popular activity across many policy spheres. Many state and city governments and the EPA see brownfield remediation as a priority, and indubitably thousands of cleanups will occur across the United States in the near future.

The empirical findings of this paper suggest that brownfield remediation reduces nearby property values. There is substantial heterogeneity in the property value impacts over space; we 
find that the overall negative effects are driven by low-income neighborhoods. These findings lead us to conclude that there is incomplete information about contamination prior to remediation and discovery of contamination increases concern about nearby properties among current residents and potential buyers, as well as mortgage lenders and developers.

The unequal and regressive distribution of impacts raises concerns about the popularity of brownfield remediation programs. Future research should strive to understand how individual programs and policies can be altered to avoid unintended consequences. Comparing our results to those of Haninger et al. (2017) suggests that external funding and community involvement may be critical for positive outcomes to be realized, and this supports the institutional understanding of experts at the EPA (Cooper et al. 2015). Interestingly, Rhode Island held and passed referendums in the 2014 and 2016 elections that provide a combined \$10 million of matching grants for new brownfield remediation project costs. We are interested to see if this funding can alleviate the problems observed with the program thus far, but would additionally encourage community outreach and information dissemination to be coupled with this funding.

\section{REFERENCES}

Apelberg, B. J., Buckley, T. J., \& White, R. H. (2005). Socioeconomic and racial disparities in cancer risk from air toxics in Maryland. Environmental health perspectives, 113(6), 693.

Bajari, P., Fruehwirth, J. C., Kim, K. I., \& Timmins, C. (2012). A rational expectations approach to hedonic price regressions with time-varying unobserved product attributes: The price of pollution. The American Economic Review, 102(5), 1898-1926.

Baumol, William J. and Wallace E. Oates. (1988). The Theory of Environmental Policy, New York: Cambridge University Press, Second Edition.

Been, V. (1994). Locally undesirable land uses in minority neighborhoods: Disproportionate siting or market dynamics?. Yale Law Journal, 1383-1422.

Bento, A., Freedman, M., \& Lang, C. (2015). Who benefits from environmental regulation? evidence from the clean air act amendments. Review of Economics and Statistics, 97(3), 610622.

Brooks, N., \& Sethi, R. (1997). The distribution of pollution: community characteristics and exposure to air toxics. Journal of Environmental Economics and Management, 32(2), 233250. 
Ciesielski, T., Weuve, J., Bellinger, D. C., Schwartz, J., Lanphear, B., \& Wright, R. O. (2012). Cadmium exposure and neurodevelopmental outcomes in US children. Environmental health perspectives, 120(5), 758.

Cogliano, V. J. (1998). Assessing the cancer risk from environmental PCBs. Environmental Health Perspectives, 106(6), 317.

Cooper, Gail Ann, David Lloyd, Brigid Lowery and Karen Sullivan. Personal communication, June 17, 2015.

Croen, L. A., Shaw, G. M., Sanbonmatsu, L., Selvin, S., \& Buffler, P. A. (1997). Maternal residential proximity to hazardous waste sites and risk for selected congenital malformations. Epidemiology, 8(4), 347-354.

Currie, J., Davis, L., Greenstone, M., \& Walker, R. (2013). Do housing prices reflect environmental health risks? Evidence from more than 1600 toxic plant openings and closings (No. w18700). National Bureau of Economic Research.

Depro, B., Timmins, C., \& O’Neil, M. (2015). White flight and coming to the nuisance: can residential mobility explain environmental injustice?. Journal of the Association of Environmental and resource Economists, 2(3), 439-468.

Environmental Protection Agency. (2014). Brownfields Grant Fact Sheet Search. Accessed October 9, 2014.

Fullerton, D. (2011). Six distributional effects of environmental policy. Risk analysis, 31(6), 923929.

Gamper-Rabindran, S., \& Timmins, C. (2013). Does cleanup of hazardous waste sites raise housing values? Evidence of spatially localized benefits. Journal of Environmental Economics and Management, 65(3), 345-360.

Government Accountability Office. (2005). Remediation Activities Account for a Small Percentage of Total Brownfield Grant Funding. GAO-06-7

Grainger, C. A. (2012). The distributional effects of pollution regulations: Do renters fully pay for cleaner air?. Journal of Public Economics, 96(9), 840-852.

Greenstone, M., \& Gallagher, J. (2008). Does hazardous waste matter? Evidence from the housing market and the superfund program. The Quarterly Journal of Economics, 123(3), 951-1003.

Guignet, D. (2013). What do property values really tell us? a hedonic study of underground storage tanks. Land Economics, 89(2), 211-226.

Haninger, K., Ma, L., \& Timmins, C. (2017). The value of brownfield remediation. Journal of the Association of Environmental and Resource Economists, 4(1), 197-241.

Harding, J. P., Rosenblatt, E., \& Yao, V. W. (2009). The contagion effect of foreclosed properties. Journal of Urban Economics, 66(3), 164-178.

Kiel, K. A., \& Williams, M. (2007). The impact of Superfund sites on local property values: Are all sites the same?. Journal of urban Economics, 61(1), 170-192.

Kuminoff, N. V., \& Pope, J. C. (2013). The value of residential land and structures during the great housing boom and bust. Land Economics, 89(1), 1-29. 
Kuminoff, N. V., \& Pope, J. C. (2014). Do “Capitalization Effects” for Public Goods Reveal the Public's Willingness to Pay?. International Economic Review, 55(4), 1227-1250.

Landvoigt, T., Piazzesi, M., \& Schneider, M. (2015). The housing market (s) of San Diego. The American Economic Review, 105(4), 1371-1407.

Lang, C. (2015). The dynamics of house price responsiveness and locational sorting: Evidence from air quality changes. Regional Science and Urban Economics, 52, 71-82.

Linn, J. (2013). The effect of voluntary brownfields programs on nearby property values: Evidence from Illinois. Journal of Urban Economics, 78, 1-18.

Mastromonaco, R. A. (2014). Hazardous waste hits Hollywood: Superfund and housing prices in Los Angeles. Environmental and Resource Economics, 59(2), 207-230.

Messer, K. D., Schulze, W. D., Hackett, K. F., Cameron, T. A., \& McClelland, G. H. (2006). Can stigma explain large property value losses? The psychology and economics of superfund. Environmental and Resource Economics, 33(3), 299-324.

Pastor, M., Morello-Frosch, R., \& Sadd, J. L. (2005). The air is always cleaner on the other side: Race, space, and ambient air toxics exposures in California. Journal of urban affairs, 27(2), 127-148.

Pope, J. C. (2008). Buyer information and the hedonic: the impact of a seller disclosure on the implicit price for airport noise. Journal of Urban Economics, 63(2), 498-516.

Shaikh, S. L., \& Loomis, J. B. (1999). An investigation into the presence and causes of environmental inequity in Denver, Colorado. The Social Science Journal, 36(1), 77-92.

Taylor, L. O. (2017). Hedonics. In A Primer on Nonmarket Valuation (pp. 235-292). Springer Netherlands.

United Church of Christ. (1987). Toxic wastes and race in the United States: A national report on the racial and socio-economic characteristics of communities with hazardous waste sites. New York. Public Access Data, Inc.

Walsh, P., \& Mui, P. (2017). Contaminated sites and information in hedonic models: An analysis of a NJ property disclosure law. Resource and Energy Economics, 50, 1-14.

Wuana, R. A., \& Okieimen, F. E. (2011). Heavy metals in contaminated soils: a review of sources, chemistry, risks and best available strategies for remediation. Isrn Ecology, 2011. 


\section{Tables and Figures}

Table 1: Summary Statistics

\begin{tabular}{|c|c|c|c|c|}
\hline Variables & $\begin{array}{c}\text { In-sample } \\
\text { mean } \\
\text { (std. dev.) } \\
(1)\end{array}$ & $\begin{array}{l}\text { In vs. out of } \\
\text { sample } \\
\text { (std. error) } \\
\text { (2) }\end{array}$ & $\begin{array}{l}\text { Relationship } \\
\text { with BDI } \\
\text { (std. error) } \\
\text { (3) }\end{array}$ & $\begin{array}{l}\text { Relationship } \\
\text { with BDI, with } \\
\text { block group FE } \\
\text { (std. error) } \\
\text { (4) }\end{array}$ \\
\hline BDI & $\begin{array}{c}1.979 \\
(2.883)\end{array}$ & & & \\
\hline BDI total & $\begin{array}{c}4.528 \\
(4.724)\end{array}$ & & & \\
\hline Sales price $(2013 \$)$ & $\begin{array}{c}248,583 \\
(184,593)\end{array}$ & $\begin{array}{c}-75,225^{* *} \\
(2,144)\end{array}$ & $\begin{array}{c}-7,938 * * \\
(303)\end{array}$ & $\begin{array}{c}-6,544^{* *} \\
(1,785)\end{array}$ \\
\hline Lot size (acres) & $\begin{array}{c}0.282 \\
(0.604)\end{array}$ & $\begin{array}{c}-0.671^{* *} \\
(0.012)\end{array}$ & $\begin{array}{c}-0.022 * * \\
(0.001)\end{array}$ & $\begin{array}{c}-0.001 \\
(0.001)\end{array}$ \\
\hline Living area (square feet) & $\begin{array}{l}1,480 \\
(622)\end{array}$ & $\begin{array}{c}-166.7^{* *} \\
(5.2)\end{array}$ & $\begin{array}{c}-0.887 \\
(1.031)\end{array}$ & $\begin{array}{c}2.177 \\
(3.389)\end{array}$ \\
\hline Central AC (1=yes) & $\begin{array}{c}0.257 \\
(0.437)\end{array}$ & $\begin{array}{c}-0.087^{* *} \\
(0.003)\end{array}$ & $\begin{array}{c}-0.014^{* *} \\
(0.001)\end{array}$ & $\begin{array}{l}-0.002 * \\
(0.001)\end{array}$ \\
\hline Number of bathrooms & $\begin{array}{c}1.665 \\
(0.704)\end{array}$ & $\begin{array}{c}-0.187 * * \\
(0.005)\end{array}$ & $\begin{array}{c}-0.015 * * \\
(0.001)\end{array}$ & $\begin{array}{c}-0.003 \\
(0.003)\end{array}$ \\
\hline Median family income & $\begin{array}{c}47,210 \\
(16,728)\end{array}$ & $\begin{array}{c}-9,178 * * \\
(122)\end{array}$ & $\begin{array}{c}-1,322^{* *} \\
(26)\end{array}$ & \\
\hline Proportion college graduate & $\begin{array}{c}0.264 \\
(0.168)\end{array}$ & $\begin{array}{c}-0.046^{* *} \\
(0.001)\end{array}$ & $\begin{array}{c}-0.005^{* *} \\
(0.001)\end{array}$ & \\
\hline Proportion non-white & $\begin{array}{c}0.112 \\
(0.155)\end{array}$ & $\begin{array}{l}0.054 * * \\
(0.001)\end{array}$ & $\begin{array}{c}0.020 * * \\
(0.001)\end{array}$ & \\
\hline
\end{tabular}

Notes: BDI is the sum of the inverse distances to all brownfields within $2 \mathrm{~km}$ of a housing transaction that were remediated prior to the transaction. BDI total is a time invariant measure that equals the sum of the inverse distances to all brownfields within $2 \mathrm{~km}$ of a housing transaction, regardless of remediation status. Median income, proportion of college graduates and proportion non-white come from the 2000 Decennial Census at the block group level. For Column 2, variables were regressed on an indicator for in-sample. For Columns 3 and 4, variables were regressed on BDI, and, in Column 4, block group fixed effects. In each of Columns 2-4, the regression coefficient and standard error are displayed. Sample size is 43,787 for columns 1,3 and 4 and is 78,415 for column 2 . ${ }^{*}$ and $* *$ indicate significance at $5 \%$ and $1 \%$, respectively. 
Table 2 : The Effect of Brownfield Remediation on Housing Prices

\begin{tabular}{|c|c|c|c|c|c|}
\hline \multirow{2}{*}{ Variables } & \multicolumn{5}{|c|}{$\begin{array}{c}\text { Dependent Variable: Log Sales Price } \\
\end{array}$} \\
\hline & (1) & (2) & (3) & (4) & (5) \\
\hline \multicolumn{6}{|l|}{ Panel A: total effect of remediation } \\
\hline BDI & $\begin{array}{c}-0.0249 * * * \\
(0.0041)\end{array}$ & $\begin{array}{c}-0.0183 * * * \\
(0.0038)\end{array}$ & $\begin{array}{c}-0.0128 * * * \\
(0.0033)\end{array}$ & $\begin{array}{c}-0.0119 * * * \\
(0.0031)\end{array}$ & $\begin{array}{c}-0.0100^{* * *} \\
(0.0027)\end{array}$ \\
\hline Adjusted R-squared & 0.597 & 0.704 & 0.717 & 0.733 & 0.737 \\
\hline \multicolumn{6}{|l|}{$\begin{array}{l}\text { Panel B: effect of remediation split by time } \\
\text { horizon }\end{array}$} \\
\hline BDI 0-6 months & $\begin{array}{c}-0.0294 * * * \\
(0.0050)\end{array}$ & $\begin{array}{c}-0.0158 * * * \\
(0.0043)\end{array}$ & $\begin{array}{c}-0.0110 * * * \\
(0.0041)\end{array}$ & $\begin{array}{c}-0.0094^{* *} \\
(0.0039)\end{array}$ & $\begin{array}{c}-0.0080 * * \\
(0.0038)\end{array}$ \\
\hline BDI 6-18 months & $\begin{array}{c}-0.0221 * * * \\
(0.0077)\end{array}$ & $\begin{array}{c}-0.0146 * * * \\
(0.0051)\end{array}$ & $\begin{array}{c}-0.0102 * * \\
(0.0042)\end{array}$ & $\begin{array}{c}-0.0085^{* *} \\
(0.0036)\end{array}$ & $\begin{array}{c}-0.0077 * * \\
(0.0033)\end{array}$ \\
\hline BDI 18 or more months & $\begin{array}{c}-0.0245 * * * \\
(0.0043)\end{array}$ & $\begin{array}{c}-0.0193 * * * \\
(0.0042)\end{array}$ & $\begin{array}{c}-0.0147 * * * \\
(0.0040)\end{array}$ & $\begin{array}{c}-0.0142 * * * \\
(0.0037)\end{array}$ & $\begin{array}{c}-0.0116^{* * *} \\
(0.0033)\end{array}$ \\
\hline Adjusted R-squared & 0.591 & 0.703 & 0.716 & 0.733 & 0.736 \\
\hline Housing and neighborhood characteristics & Yes & Yes & Yes & Yes & Yes \\
\hline Year-month FE & No & Yes & Yes & Yes & Yes \\
\hline Census Block Group FE & No & No & Yes & Yes & Yes \\
\hline Town X Year FE & No & No & No & Yes & Yes \\
\hline Pre-sample mean price $\mathrm{X}$ year-quarter FE & No & No & No & No & Yes \\
\hline Observations & 43,787 & 43,787 & 43,787 & 43,787 & 43,787 \\
\hline
\end{tabular}

Notes: Each column of each panel results from a separate regression. In Panel A, BDI is the sum of the inverse distances to all brownfields within $2 \mathrm{~km}$ of a housing transaction that were remediated prior to the transaction. In Panel B, a remediated brownfield only enters the BDI measure if it occurs in the time span specified by the variable. Housing and neighborhood characteristics include lot size, living area, house age bins, bedrooms, full bathrooms, half bathrooms, floors, parking spaces, total rooms, fireplaces, pool, central air conditioning, water view, and distance to the nearest: coastline, lake, river, village center, downtown Providence, industrial area, impoverished area, and pre-sample CERCLIS site. Pre-sample mean prices are census tract average sales prices for pre-sample years 2001-2003. Standard errors are shown in parentheses and are estimated using the Eicker-White formula to correct for heteroskedasticity and are clustered at the block group level. *, ** and *** indicate significance at $10 \%, 5 \%$ and $1 \%$, respectively. 
Table 3: Robustness Checks

\begin{tabular}{|c|c|c|c|c|c|c|}
\hline \multirow[b]{2}{*}{ Variables } & \multicolumn{6}{|c|}{ "Dependent Variable: Log Sales Price } \\
\hline & $\begin{array}{c}\text { Repeat sales } \\
\text { (1) } \\
\end{array}$ & $\begin{array}{l}\text { Include } \\
\text { time- } \\
\text { invariant } \\
\text { BDI total } \\
\quad(2) \\
\end{array}$ & $\begin{array}{c}\text { Tract X year } \\
\text { FE } \\
\text { (3) }\end{array}$ & $\begin{array}{l}\text { Pre-sample } \\
\text { sales price as } \\
\text { predictor } \\
\text { (4) }\end{array}$ & $\begin{array}{l}\text { Use distance } \\
\text { squared in } \\
\text { BDI } \\
\text { calculation } \\
\text { (5) } \\
\end{array}$ & $\begin{array}{c}\text { Use root } \\
\text { distance in } \\
\text { BDI } \\
\text { calculation } \\
(6) \\
\end{array}$ \\
\hline BDI & $\begin{array}{c}-0.0134^{* * *} \\
(0.0031)\end{array}$ & $\begin{array}{c}-0.0103 * * * \\
(0.0023)\end{array}$ & $\begin{array}{c}-0.0085 * * \\
(0.0035)\end{array}$ & $\begin{array}{c}-0.0187^{* * *} \\
(0.0031)\end{array}$ & $\begin{array}{c}-0.0022 * * * \\
(0.0004)\end{array}$ & $\begin{array}{c}-0.0190^{* * * *} \\
(0.0023)\end{array}$ \\
\hline BDI total & & $\begin{array}{l}-0.0004 \\
(0.0021)\end{array}$ & & & & \\
\hline Housing and neighborhood characteristics & Yes & Yes & Yes & Yes & Yes & Yes \\
\hline Year-month FE & Yes & Yes & Yes & Yes & Yes & Yes \\
\hline Census Block Group FE & No & Yes & Yes & Yes & Yes & Yes \\
\hline Town X Year FE & Yes & Yes & No & Yes & Yes & Yes \\
\hline Pre-sample mean price $\mathrm{X}$ year-quarter FE & Yes & Yes & No & No & Yes & Yes \\
\hline Property FE & Yes & No & No & No & No & No \\
\hline Tract $\mathrm{X}$ year FE & No & No & Yes & No & No & No \\
\hline Pre-sample sales price $\mathrm{X}$ year-quarter FE & No & No & No & Yes & No & No \\
\hline Observations & 17,506 & 43,787 & 35,711 & 9,836 & 43,742 & 43,787 \\
\hline Adjusted R-squared & 0.859 & 0.723 & 0.717 & 0.789 & 0.723 & 0.724 \\
\hline
\end{tabular}

Notes: The Column 1 sample includes only properties that transact more than once, and the model includes property-specific fixed effects. Column 2 includes as an independent variable BDI total, which is the sum of the inverse distances to all brownfields, remediated and unremediated, within $2 \mathrm{~km}$ of a housing transaction. Column 3 adds Census Tract by year fixed effects to the Table 2 Column 5 specification and removes year-town FEs and pre-sample neighborhood mean price interacted with yearquarter FEs. Column 3 only includes tracts with more than 200 observations in the sample. The Column 4 sample includes only properties that transacted January 2000September 2003 as well as the sample time frame October 2003-March 2013; then the pre-sample sales price (inflation adjusted and logged) is interacted with year-quarter fixed effects. For Columns 5 and 6, the definition of BDI is altered. Modifying Equation (1) to have an exponent on inverse distance, $B D I_{i}=\sum_{J}\left(\frac{1}{d_{i, j}}\right)^{p} \cdot 1\left(t_{i}>t_{j}\right)$.

$1\left(d_{i, j}<2 k m\right)$, Column 5 sets $\mathrm{p}=2$ and Column 6 sets $\mathrm{p}=0.5$, as compared to the main results that set $\mathrm{p}=1$. Squaring inverse distance produces a distribution of BDI with a long right tail; Column 5 drops transactions in the top $0.1 \%$ of the BDI distribution to reduce influence of outliers. See Table 2 for more details. 
Table 4: Heterogeneous Effects of Brownfield Remediation by Neighborhood Value

\begin{tabular}{|c|c|c|c|}
\hline \multirow{2}{*}{ Variables } & \multicolumn{3}{|c|}{ "Dependent Variable: Log Sales Price } \\
\hline & $(1)$ & $(2)$ & (3) \\
\hline BDI X I(low price neighborhood) & $\begin{array}{c}-0.0208 * * * \\
(0.0024)\end{array}$ & $\begin{array}{c}-0.0205 * * * \\
(0.0024)\end{array}$ & $\begin{array}{c}-0.0181 * * * \\
(0.0037)\end{array}$ \\
\hline BDI X I(medium price neighborhood) & $\begin{array}{c}-0.0078^{* *} \\
(0.0040)\end{array}$ & $\begin{array}{l}-0.0024 \\
(0.0037)\end{array}$ & $\begin{array}{l}-0.0092 * \\
(0.0049)\end{array}$ \\
\hline BDI X I(high price neighborhood) & $\begin{array}{l}-0.0010 \\
(0.0019)\end{array}$ & $\begin{array}{c}0.0070 * * \\
(0.0030)\end{array}$ & $\begin{array}{l}0.0115^{*} \\
(0.0059)\end{array}$ \\
\hline BDI total X I(low price neighborhood) & & $\begin{array}{c}0.0023 \\
(0.0019)\end{array}$ & \\
\hline BDI total X I(medium price neighborhood) & & $\begin{array}{c}-0.0079 * * \\
(0.0039)\end{array}$ & \\
\hline BDI total X I(high price neighborhood) & & $\begin{array}{c}-0.0101 * * * \\
(0.0034)\end{array}$ & \\
\hline Census block group FE & Yes & Yes & No \\
\hline Property FE & No & No & Yes \\
\hline Observations & 43,787 & 43,787 & 17,506 \\
\hline Adjusted R-squared & 0.724 & 0.724 & 0.860 \\
\hline \multicolumn{4}{|c|}{$\begin{array}{l}\text { Notes: Each column shows a single regression. Each regression includes housing and neighborhood characteristics, } \\
\text { year-month fixed effects, year-town fixed effects, and neighborhood pre-sample mean price interacted with year- } \\
\text { quarter fixed effects. In columns } 1 \text { and 2, the sample is identical to Table 2. In Column 3, only properties transacting } \\
\text { more than once are included. Neighborhoods (defined by census block groups) are sorted into three categories of } \\
\text { low, medium and high house prices based on average sales price for January 2000-September 2003. I(low price } \\
\text { neighborhood), I(medium price neighborhood) and I(high price neighborhood) are indicator variables based on that } \\
\text { categorization. "X" indicates an interaction between two variables. See Table } 2 \text { for more details. }\end{array}$} \\
\hline
\end{tabular}


Table 5: Heterogeneous Effects of Brownfield Remediation by Contamination Source and Reuse Type

\begin{tabular}{lcccc}
\hline \hline Panel A: Contamination Source & Historical & Synthetic compounds & Petroleum & Other \\
$(3)$ & $(2)$ & -0.0064 & $-0.0089 * *$ & $-0.0162 * * *$ \\
$(1)$ & $-0.0073 * *$ & $(0.0041)$ & $(0.0044)$ & $(0.0034)$ \\
\hline BDI & $(0.0033)$ & \multicolumn{3}{c}{} \\
& Commercial & Residential & Industrial & Other \\
Panel B: Reuse Type & $(5)$ & $(6)$ & $(7)$ & $(8)$ \\
\hline BDI & $-0.0089 * *$ & $-0.0069 * *$ & $-0.0205^{* * *}$ & $-0.0217^{* * *}$ \\
& $(0.0035)$ & $(0.0032)$ & $(0.0050)$ & $(0.0038)$ \\
\hline
\end{tabular}

Notes: Each column of each panel represents a separate regression, each with only one type of brownfield included in the calculation of BDI For this table, BDI is calculated as the sum of inverse distances for all remediated brownfields of that type at the time of sale. "Historical" indicates a site of past manufacturing. "Synthetic compounds" include heavy metals and polychlorinated biphenyls. "Residential" includes both housing and schools. For contamination, "Other" either indicates that the contamination was unknown or there were too few instances of that type to form a group. For reuse, "Other" either indicates that there were too few instances of that type to form a group or there was no reuse occurring. All models include all controls used in Column 5 of Table 2 and have a sample size of 43,787. See Table 2 in the main text for more details. 
Figure 1: Hedonic price schedule for environmental quality

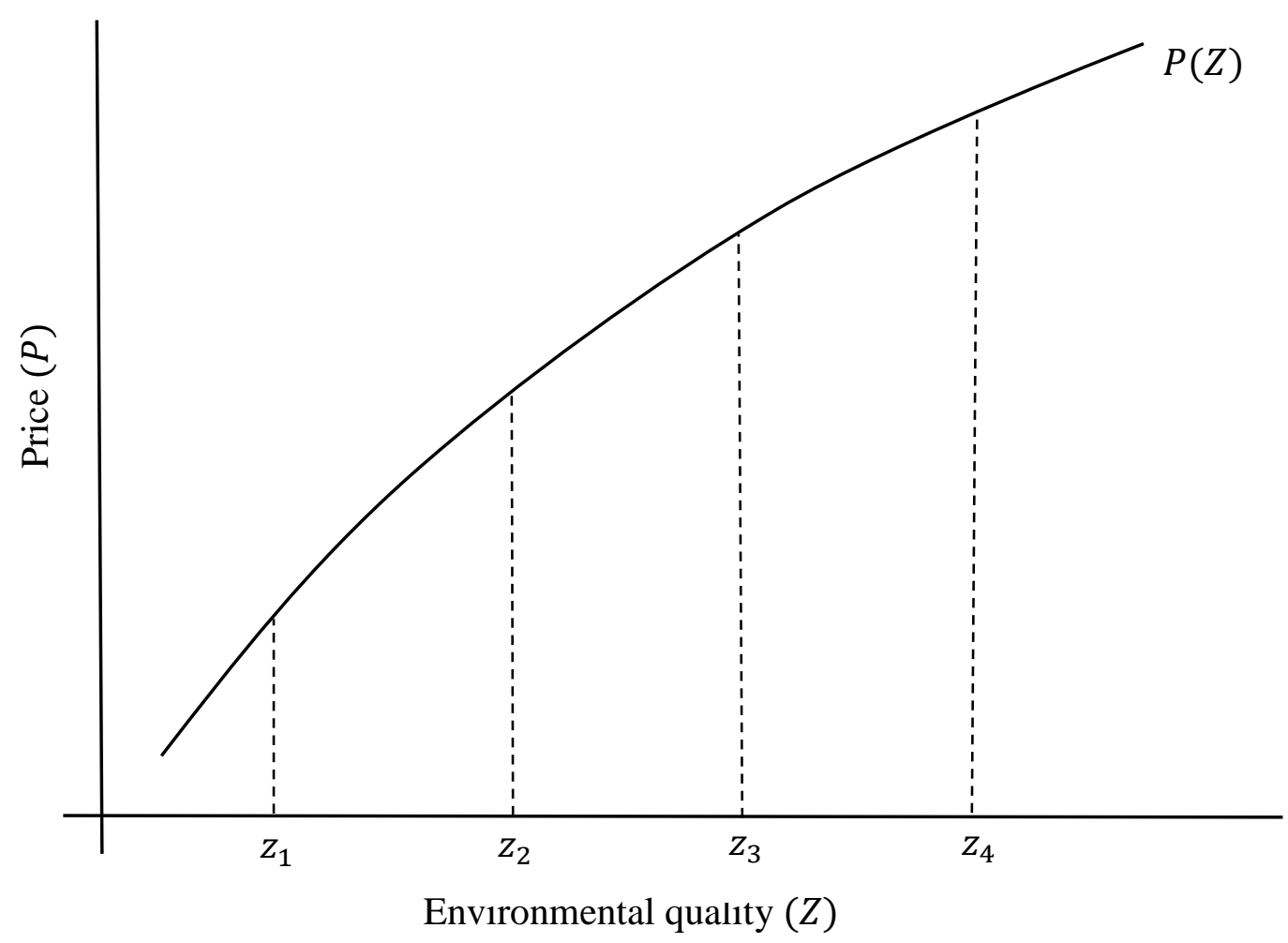


Figure 2: Distributional impacts of brownfield remediation

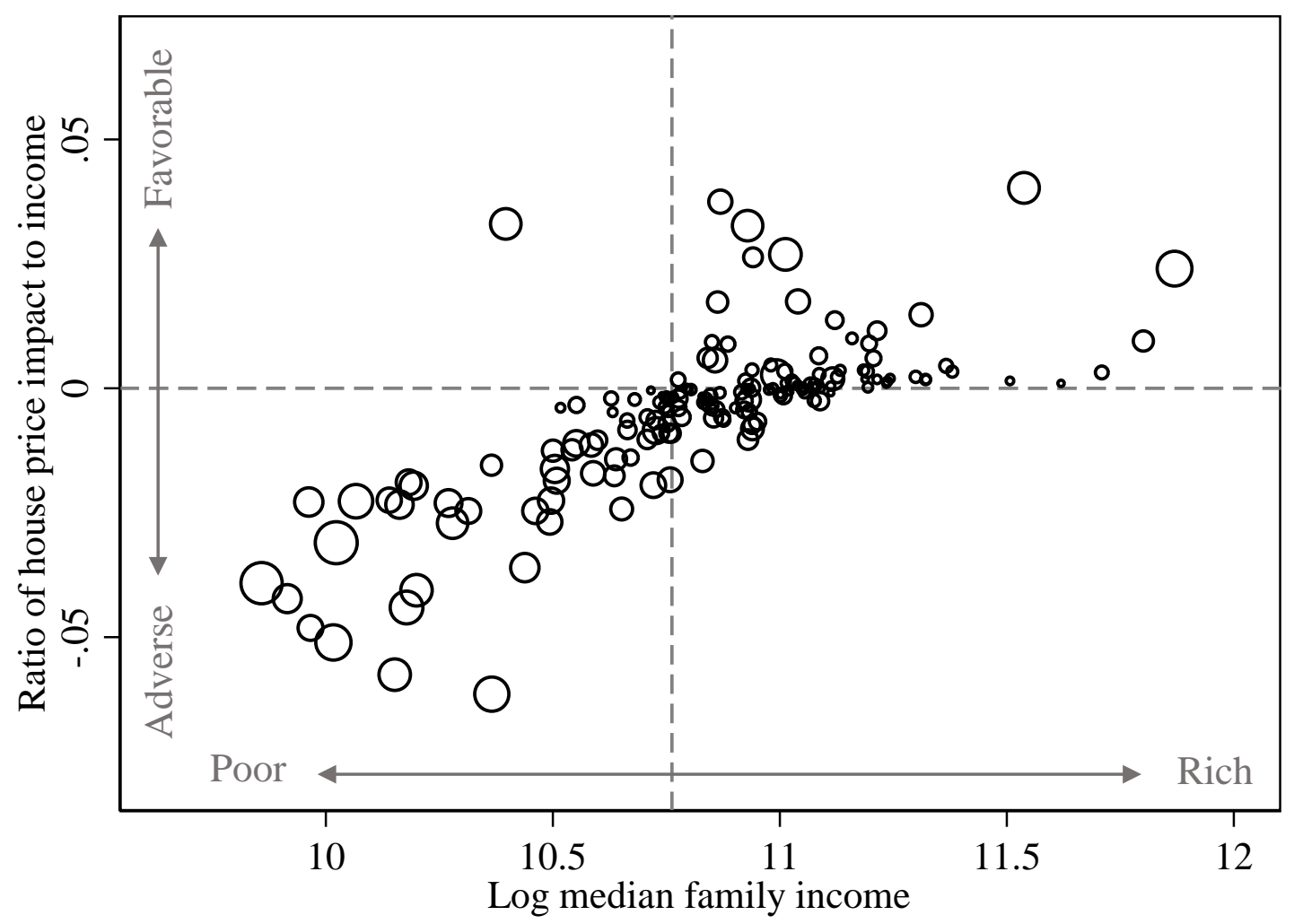

Notes: Using results from Column 3 of Table 4, sales prices are multiplied by BDI and by the corresponding coefficient estimate to arrive at the total impact of remediation on sales price. This number is then put in annual terms assuming a 5\% interest rate and 30-year mortgage. Annualized impacts are averaged by Census tract and divided by tract median family income from the 2000 Decennial Census to arrive at the y-axis value. Only tracts with 50 or more transactions in the sample are plotted ( $N=163$, representing $98.4 \%$ of the main sample). Circle diameter is proportional to the average BDI of all observations within a tract, thus larger circles indicate neighborhoods that experienced more remediation. The mean of log median family income is 10.76, which translates into $\$ 47,210$, and this appears as a vertical line on the graph. 


\title{
Online Appendix
}

\author{
INCOMPLETE INFORMATION AND ADVERSE IMPACTS \\ OF ENVIRONMENTAL CLEANUP \\ Corey Lang and Patrick Cavanagh \\ University of Rhode Island \\ (not for publication)
}

This appendix provides information, data, and results that supplement, but are not critical to, the analysis in our main paper.

Figure A1 shows the geographic distribution of the 225 sample brownfields.

Figure A2 shows the average sales price trend for our sample. This plot reveals the increase in prices at the beginning of our sample period and the sharp downward trend at the onset of the housing crisis.

Figures A3a and A3b show neighborhood average price changes as a function of initial prices for the boom period 2002-2006 and the bust period 2006-2011, respectively. During 20022006, low price neighborhoods increased in value about 20 percentage points more than high price neighborhoods. During 2006-2011, those low price neighborhoods experienced far greater price declines. These findings motivate inclusion of average pre-sample house prices by tract interacted with year-quarter fixed effects.

Table A1 gives frequency counts for contamination source and reuse type for our sample of 225 brownfields.

Table A2 gives sample means and standard deviations for all independent variables included in our hedonic regressions.

\section{Difference-in-differences}

One concern about the main results is that the dose-response modeling strategy could be driving the results. Difference-in-differences is a commonly applied research design and is typically better suited to modeling a counterfactual that standard linear regression. Thus, it makes sense to apply that here. The basic difference-in-differences model is: 


$$
\begin{gathered}
\ln \left(p_{i}\right)=\beta_{1} \text { treatment }_{i}+\beta_{2} \text { post_remediation }_{i}+\beta_{3} \text { treatment }_{i} \cdot \text { post_remediation }_{i} \\
+X_{i} \varphi+\varepsilon_{i}
\end{gathered}
$$

Given the close proximity of brownfields to each other and that they are remediated at different times, it is not straightforward to define treatment and control and pre and post, and we decided to anchor those definitions on the nearest brownfield. We define the treatment group as properties for which the nearest brownfield is less than $0.5 \mathrm{~km}$ away. The control group is defined as properties for which the nearest brownfield is between 1 and $2 \mathrm{~km}$ away. We omit properties for which the nearest brownfield is between 0.5 and $1 \mathrm{~km}$ away with the intent to create more contrast between treatment and control. We define post remediation as a binary variable equal to one if the nearest brownfield has been remediated and zero otherwise.

Panel A of Table A3 presents results from two difference-in-differences models, one cross sectional and one repeat sales, and only giving the coefficient on the key interaction term of the model ( $\beta_{3}$ from Equation A1). The coefficients are similar to the main results in that they are negative and highly statistically significant. The magnitudes are substantially larger, but the interpretation is different. While the variables are binary, treatment likely often involves being proximate to several brownfields due to the clustered nature of brownfields in our sample. These results suggest that the main results are not being driven by the modeling strategy.

Panel B estimates the same models as Panel A, but uses only transactions that have a single brownfield within $2 \mathrm{~km}$. These are isolated brownfields, and thus represent the cleanest treatment and control. Results here suggest a positive impact of remediation. While at first blush this appears to contradict our main findings and raises questions about our empirical strategy, the isolated brownfields occur in wealthier areas and these coefficients are consistent with the high price neighborhood results from Table 4. Thus, we do not view the Panel B results as valid treatment effects for the whole program.

Table A4 supports the difference-in-differences analysis presented in Table A3. Table A4 varies the distance bins used for definition of treatment and control. Results are qualitatively identical to Table 6 and consistent with the main results.

Difference-in-differences models that interact key variables with low, medium, and high price neighborhood indicator variables reveal similar price effects as those found in Table 4 further supporting this conclusion. 
Figure A1: Remediated Brownfield Sites, 2003-2013

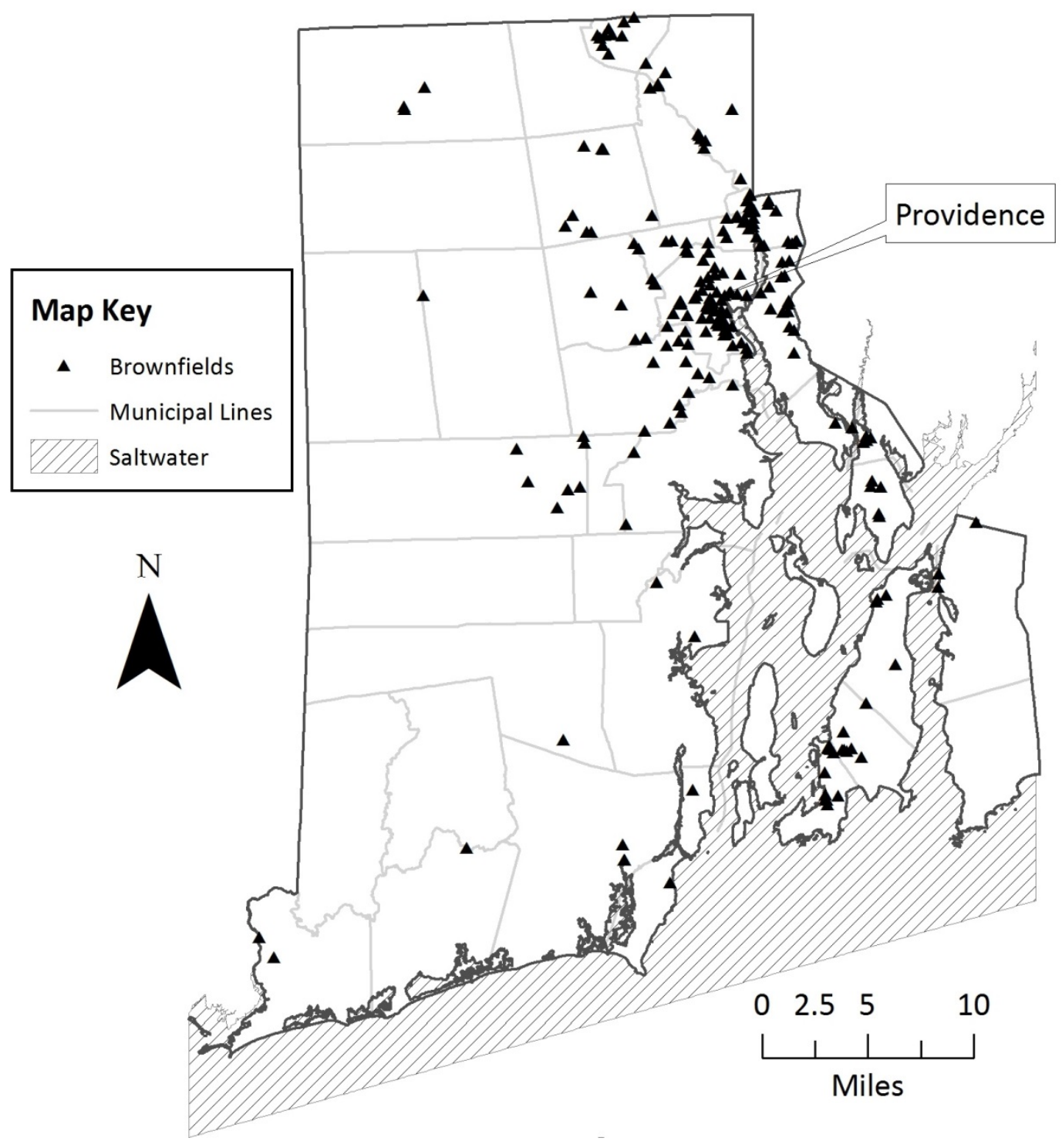


Figure A2: Sales Price Trends over Sample Period

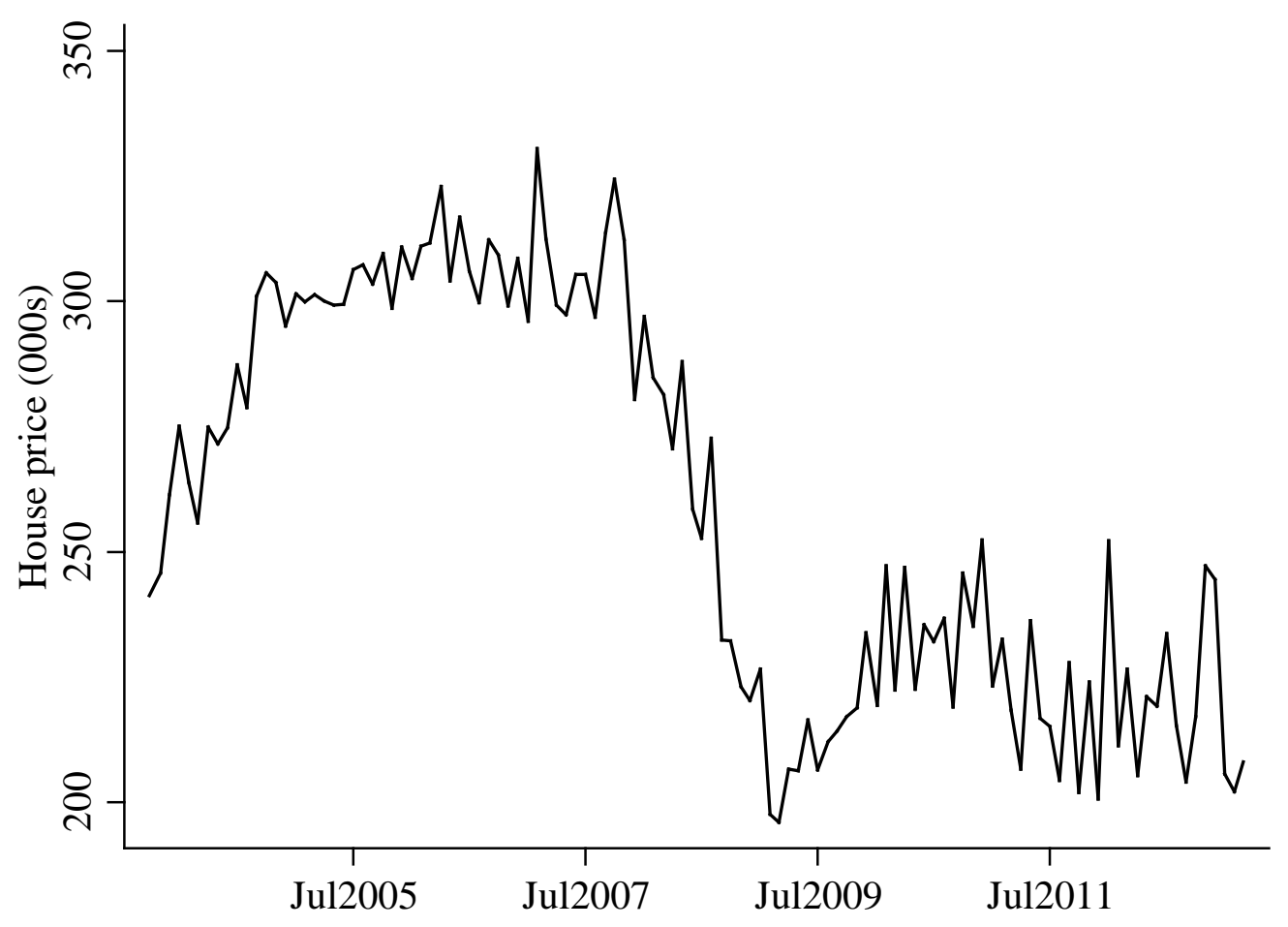

Notes: Sales prices were first regressed on month fixed effects to remove predictable annual variation. Sample size is 43,787 . 
Figure A3a: Average Neighborhood Price Changes, 2002-2006

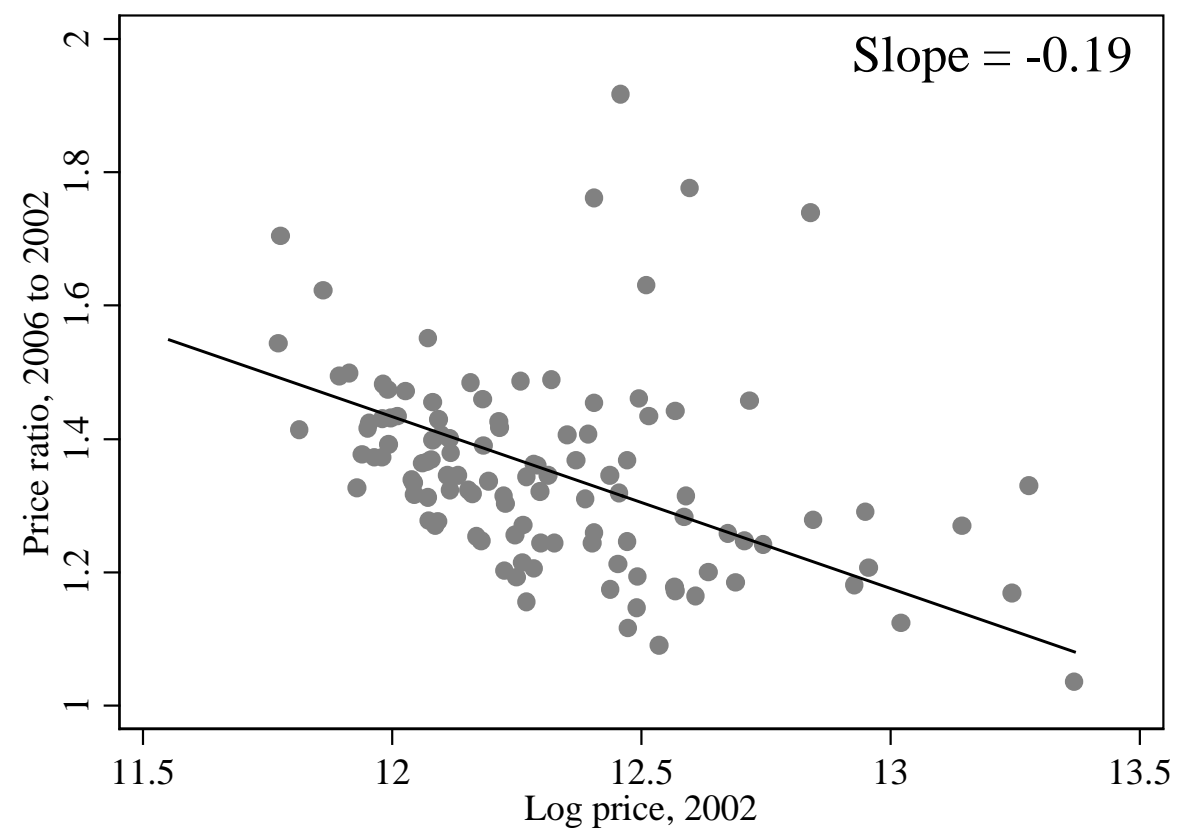

Figure A3b: Average Neighborhood Price Changes, 2006-2011

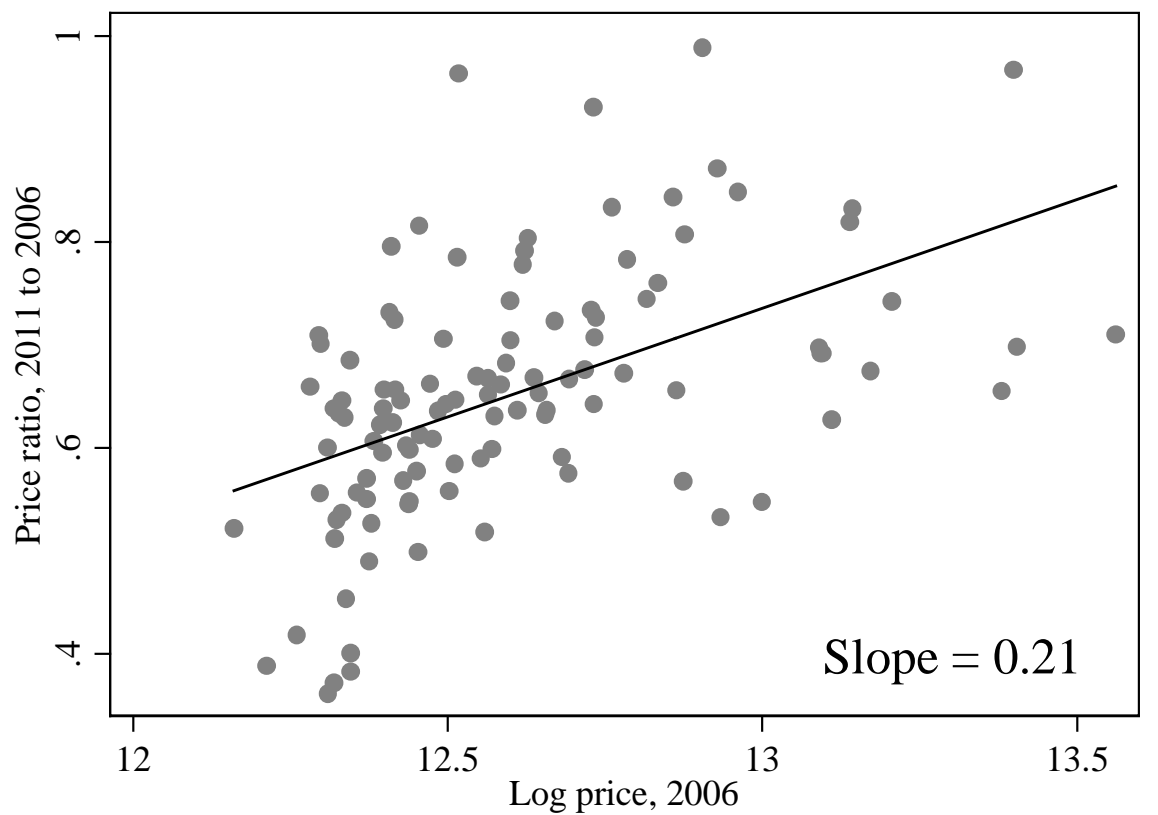

Notes: Average prices are determined for all sample neighborhoods, defined as Census Tracts, with at least 10 observations in each of 2002, 2006 and 2011. The x-axis, log price, is the log of the average neighborhood sales price. The y-axis, price ratio, is the average neighborhood sales price in the later year divided by the earlier year. 
Table A1: Transition Frequency from Contamination to Re-use

\begin{tabular}{|c|c|c|c|c|c|c|}
\hline \multirow{7}{*}{$\begin{array}{c}\text { Type of } \\
\text { contamination }\end{array}$} & & \multicolumn{4}{|c|}{ Type of Re-use } & \multirow[b]{2}{*}{ Total } \\
\hline & & Commercial & Residential & Industrial & Other & \\
\hline & Historical & 41 & 28 & 21 & 18 & 108 \\
\hline & Synthetic & 16 & 8 & 11 & 7 & 42 \\
\hline & Petroleum & 19 & 4 & 4 & 6 & 33 \\
\hline & Other & 19 & 16 & 4 & 3 & 42 \\
\hline & Total & 95 & 56 & 40 & 34 & 225 \\
\hline
\end{tabular}

Notes: Each cell represents the number of remediated brownfields that are of the given type of contamination and the given type of reuse. "Historical" indicates a site of past manufacturing. "Synthetic" stands for synthetic compounds and includes heavy metals and polychlorinated biphenyls. "Residential" includes both housing and schools. For contamination, "Other" either indicates that the contamination was unknown or there were too few instances of that type to form a group. For reuse, "Other" either indicates that there were too few instances of that type to form a group or there was no reuse occurring. 
Table A2: Housing and Neighborhood Summary Statistics

\begin{tabular}{lcc}
\hline \hline & Mean & $\begin{array}{c}\text { Standard } \\
\text { deviation }\end{array}$ \\
\cline { 2 - 3 } Sale Price (\$2013) & 248585 & 184594 \\
BDI & 1.98 & 2.88 \\
BDI 0-6 months & 0.23 & 0.71 \\
BDI 6-18 months & 0.42 & 1.16 \\
BDI 18+ months & 1.34 & 2.31 \\
BDI total & 4.53 & 4.72 \\
Lot Size (acres) & 0.28 & 0.60 \\
Number of floors & 1.29 & 0.68 \\
Number of fireplaces & 0.26 & 0.50 \\
Number of bedrooms & 3.03 & 0.79 \\
Number of full bathrooms & 1.46 & 0.63 \\
Number of half bathrooms & 0.42 & 0.52 \\
Number of parking spots & 0.08 & 0.32 \\
Living Area (100's sq. ft.) & 14.81 & 6.22 \\
Total number of rooms & 6.17 & 1.50 \\
House age at sale & 3.05 & 1.40 \\
pool (1=yes) & 0.04 & 0.19 \\
Central Air Conditioning (1=yes) & 0.26 & 0.44 \\
View of water (1=yes) & 0.00 & 0.04 \\
Distance to nearest highway exit $(\mathrm{km})$ & 3.97 & 3.94 \\
Distance to nearest village $(\mathrm{km})$ & 1.68 & 1.01 \\
Distance to downtown Providence $(\mathrm{km})$ & 14.08 & 12.43 \\
Distance to nearest lake $(\mathrm{km})$ & 1.08 & 0.69 \\
Distance to the coast $(\mathrm{km})$ & 5.46 & 5.49 \\
Distance to nearest river $(\mathrm{km})$ & 2.35 & 2.42 \\
Distance to nearest Industrial area $(\mathrm{km})$ & 0.67 & 0.56 \\
Distance to nearest Enterprise Zone $(\mathrm{km})$ & 3.15 & 6.52 \\
Distance to nearest CERCLIS site $(\mathrm{km})$ & 1.38 & 0.75 \\
Sample size & & 43,787 \\
\hline
\end{tabular}


Table A3: Difference-in-Differences Estimates of Effect of Brownfield Remediation on Housing Prices

\begin{tabular}{lc}
\multicolumn{2}{c}{ Dependent Variable: Log Sales Price } \\
Cross section & Repeat sales
\end{tabular}

(1)

Panel A: All Brownfields

Treatment*Post remediation $-0.0458 * * *$

$(0.0131)$

Observations

Adjusted R-squared
27,817

0.728
(2) $-0.0859 * * *$ (0.0240) 10,798 0.838

Panel B: Only Isolated Brownfields

$\begin{array}{lcc}\text { Treatment*Post remediation } & 0.0741^{*} & 0.0749 \\ & (0.0412) & (0.0565)\end{array}$

Observations

8,843

3,032

Adjusted R-squared

0.703

0.862

\begin{tabular}{llc}
\hline Housing and neighborhood characteristics & Yes & Yes \\
Year-month FE & Yes & Yes \\
Census Block Group FE & Yes & No \\
Town X Year FE & Yes & Yes \\
Pre-sample mean price X year-quarter FE & Yes & Yes \\
Property FE & No & Yes \\
\hline
\end{tabular}

Notes: This table presents results of four difference-in-differences regression models, each of which regress log sales price on Treatment, Post remediation, their interaction, and a suite of control variables listed at the bottom of the table. Only coefficients for the interaction are shown. Treatment is binary and equals 1 when a property is within $0.5 \mathrm{~km}$ of a brownfield site. Treatment equals 0 when the nearest brownfield to a property is between 1 and $2 \mathrm{~km}$. Properties are excluded if the nearest brownfield is between 0.5 and $1 \mathrm{~km}$. Post remediation is binary and equals 1 if the transaction occurs after the nearest brownfield is remediated and 0 otherwise. Panel B only includes properties that have only a single brownfield within $2 \mathrm{~km}$. See Table 2 for more details. 
Table A4: Difference-in-Differences Estimates of Effect of Brownfield Remediation on Housing Prices, varying distances that define treatment and control

\begin{tabular}{|c|c|c|c|c|}
\hline \multirow{4}{*}{$\begin{array}{l}\text { Treatment distance band }(\mathrm{km}) \text { : } \\
\text { Control distance band }(\mathrm{km}) \text { : }\end{array}$} & \multicolumn{4}{|c|}{ Dependent Variable: Log Sales Price } \\
\hline & $0-0.5$ & $0-0.5$ & $0-0.75$ & $0-0.3$ \\
\hline & $1-2$ & $0.5-2$ & $1-2$ & $1-2$ \\
\hline & (1) & (2) & (3) & (4) \\
\hline \multicolumn{5}{|l|}{ Panel A: All Brownfields } \\
\hline Treatment*Post remediation & $\begin{array}{c}-0.0458 * * * \\
(0.0131)\end{array}$ & $\begin{array}{c}-0.0258 * * \\
(0.0106)\end{array}$ & $\begin{array}{c}-0.0384 * * * \\
(0.0102)\end{array}$ & $\begin{array}{c}-0.0538 * * * \\
(0.0208)\end{array}$ \\
\hline Observations & 27,817 & 43,827 & 36,316 & 22,813 \\
\hline R-squared & 0.7276 & 0.7232 & 0.7275 & 0.7244 \\
\hline \multicolumn{5}{|c|}{ Panel B: Only Isolated Brownfields } \\
\hline Treatment*Post remediation & $\begin{array}{l}0.0741^{*} \\
(0.0412)\end{array}$ & $\begin{array}{l}0.0687 * \\
(0.0369)\end{array}$ & $\begin{array}{c}0.0403 \\
(0.0255)\end{array}$ & $\begin{array}{c}0.1341 \\
(0.0963)\end{array}$ \\
\hline Observations & 8,843 & 10,720 & 9,685 & 8,575 \\
\hline R-squared & 0.7029 & 0.6943 & 0.7031 & 0.7019 \\
\hline
\end{tabular}

Notes: This table presents eight regression results of Equation A1. For each column, the distance bands that define treatment and control are different and are listed at the top of each column. For example, in column 1, treatment equals 1 when a property is within $0.5 \mathrm{~km}$ of a brownfield site, treatment equals 0 when the nearest brownfield to a property is between 1 and $2 \mathrm{~km}$, and properties are excluded if the nearest brownfield is between 0.5 and $1 \mathrm{~km}$. Post remediation is binary and equals 1 if the transaction occurs after the nearest brownfield is remediated and 0 otherwise. Panel B only includes properties that have only a single brownfield within $2 \mathrm{~km}$. See Table 2 in the main text for more details. 